\title{
ROADSIDE PUBLIC SURVEY APPROACH IN BLACK SPOT IDENTIFICATION ON RURAL ROADS: CASE STUDY
}

\author{
Miladin Nešić ${ }^{1}$, Krsto Lipovac ${ }^{2}$, Milan Vujanić ${ }^{3}$, Dragan Jovanović ${ }^{4}$ \\ ${ }^{1}$ Academy of Criminalistic and Police Studies, Belgrade, Serbia \\ ${ }^{2,3}$ Faculty of Transport and Traffic Engineering, University of Belgrade, Serbia \\ ${ }^{4}$ Faculty of Technical Sciences, University of Novi Sad, Serbia
}

Submitted 17 May 2015; resubmitted 9 August 2015; accepted 5 September 2015

\begin{abstract}
This paper examines the possibility of applying the Subjective Black Spot Identification Method on state roads. A survey was conducted using interviews about 659 drivers' attitudes on the existence of Black Spots, on nine sections of state roads in the Republic of Serbia. A total of 124 locations were obtained which drivers believed were Perceived Dangerous Locations (PDLs). A set of hypotheses was defined in order to examine whether a particular PDL is a Black Spot and the test was carried out using the Bayesian Multiple Testing (BMT). Since an actual Black Spot has not been recognized as a PDL in the survey, which consequently is not subject to the BMT, new concept that includes: frequency of mishits in identifying real 'Black Spots' (RPM) and real 'non Black Spots' (RNM) and frequency of hits in identifying real 'Black Spots' (RPH) and real 'non Black Spots' (RNH) have been therefore introduced, enabling the inclusion of this outcome in the BMT. Optimisation methods have been proposed for the optimum threshold $t$ selection with the minimization of the frequency of mishits (RPM and RNM) and maximization of the frequency of hits (RPH and RNH). Two operatively usable solutions have been offered here: if the consumption of resources and the effectiveness of spending of funds for identification are primarily low, then the best result is obtained using the optimisation with the minimization of the sum of mishits frequency. Then $t=24.7 \%$ (threshold of votes for selecting PDLs as Black Spots), and the ratio of correctly and wrongly selected Black Spots is 1:1.16. On the other hand, if the goal is to detect as many real Black Spots, regardless of the reduction in the effectiveness of spending of funds, then the optimisation with the equalizing of the frequencies of mishits gives the best results. In that case, $t=7.7 \%$, and the ratio of correctly and wrongly selected Black Spots is 1:7.15.
\end{abstract}

Keywords: black spot; pre-identification; drivers attitudes survey; perceived dangerous locations; Bayesian multiple testing; optimisation.

\section{Introduction}

Most of the European countries consider Black Spot Management (BSM) to be one of the most important single infrastructural road safety measure to reduce road accident casualties. During 2008, the BSM was implemented by 22 European countries: in Great Britain, a certain form of the BSM has been implemented since the mid 1970's; in the Netherlands - since 1975, in Greece - since the end of 1980's, and in France - since 1990's (CEDR 2008).

The term Black Spot has been defined in various ways (Geurts, Wets 2003; Hauer 1996; ERF 2002a, 2002b; PIARC 2003; Sørensen, Elvik 2007; Elvik 1988, 2003, 2007; Sørensen 2007).

Elvik $(1988,2007)$ gave a significant contribution to the theoretical definition of Black Spot: black spots can be defined as '... any location that has a higher expected number of accidents than other similar locations as a result of local risk factors. The ERF (2002b) stated that the Dangerous Site is often defined in road safety programmes as: '... a site with a 'high risk' for drivers'. Vujanić et al. (2008) and Lipovac et al. (2009), based on the ERF definition (ERF 2002a, 2002b), proposed a slight correction of the definition given by Elvik (1988; 2007), and defined Black Spot, in theoretical sense, as: $a$ Black Spot is a location on the road on which the expected risk of participating in traffic is higher than at any other similar locations, as a result of local risk factors. Such a definition recognizes the efforts in identifying Black Spots, not only on the basis of the number of road crashes, but also on the basis of differently stated risk for road users, including subjective risk indicators (as the main

Corresponding author: Miladin Nešić

E-mail: miladinnesic@gmail.com 
or complementary criterion). Thus, the basis for further improvement of subjective methods of identification has been formally created.

Sørensen (2007) and Sørensen, Elvik (2007) recognized that within implementation of the BSM program identification was done according to the identification principles that can be classified in two main groups: Accident based and Not accident based. According to PIARC (2003), accident based identification can be done using the following: accident frequency, accident rate, critical accident rate, equivalent property damage only index, relative severity index, combined criteria, accident prediction models and empirical Bayesian methods. There are also situations where the spatial analysis has been used for determining the kernel density when identifying the road accident clustering and identifying Black Spots or black (hazardous) zones (Flahaut et al. 2003; Anderson 2009; Xie, Yan 2013; Russo et al. 2014; De Luca et al. 2011). Some works used artificial neural networks and multivariate analysis, or difference in $V_{85 a v e r a g e}$ speed between consecutive stretches of road greater than $10 \mathrm{~km} / \mathrm{h}$, to identify Black Spots, or cluster analysis with the creation of 'hazard index' to identify 'hazardous zone' (Mauro et al. 2013), or a 'network' safety approach in order to identify the 'black' roadway segments (Dell'Acqua, Russo 2011, 2010).

Considering not accident based identification, there are examples in which the road user perception risk measurement was used for identifying Black Spots (or potential Black Spots), where this measurement was obtained on the basis of the study of public opinion (Austin et al. 1995; Schneider et al. 2001, 2004) or by collecting information by the public about the locations where road accidents have occurred (Fukuda et al. 2005; Kowtanapanich et al. 2006, 2011).

Subjective principles of Black Spot identification entails the undertaking of the attitudes survey of: road safety experts, roads authorities, road users, and various public groups with the aim of defining in a qualitative and quantitative way the risk at the certain dangerous location or potential Black Spots. In order to use subjective risk as Black Spot identification criteria, there is a need to evaluate matching of sites with high-risk levels identified according to subjective and objective risks.

There have been few attempts to use various subjective methods for Black Spot identification. Schneider et al. (2001) applied a method of combining data from police crash reports and data from pedestrian and driver perception surveys to identify locations where pedestrian crash problems exist or may exist in the near future, in a college campus. Comparing the results from two data sets showed that the respondents perceived the pedestrian crash problems on 2 of the locations where these crashes had been reported (out of 4 identified by the crash data analysis) and a high pedestrian crash risk at 2 sites where there had been few or no reported crashes. They did not compare the risk level on the locations identified with crashes with the level of high pedestrian crash risk from the perception survey. Schneider et al. (2001) also showed the Summary of literature and cited the studies (Karim 1992; Austin et al. 1995; Duncan et al. 1999) that incorporate perception, overall findings, methodology used and key findings and recommendations. Karim (1992) carried out an interview offering respondents to rank hazardous locations that were previously identified on the basis of the crash frequency data. He has found out that the campus road users are able to rank specific locations correctly according to crash frequency. Austin et al. (1995) asked parents to comment on locations along their children's walking routes to school they considered being dangerous, and the results showed that there was often very little correlation between such locations and sites with many accidents. Duncan et al. (1999) applied a modified Delphi technique conducted with 7 pedestrian safety experts, using two iterations. The expert were offered the pictures of 141 locations, out of which 1/3 (47 sites) were the sites with the 'walking along the route' accident type. Remaining sites were the ones similar to each of them (the nearby comparison site and the far away comparison site), and those on which no road accidents occurred. In the first iteration, the reviewers were asked to rank the sites from the safest to the least safe for a pedestrian to walk along the roadway. In the second iteration, the experts were given the frequencies with which their colleagues ranked the various sites from the safest to the least safe, and the reasons given for those sites ranked by at least one reviewer as being least safe. In the second iteration, the reviewers were also given information about the posted speed limit, the pedestrian volume and the total outside lane vehicular volume on a given side of the street for each site. Based on this new information, the reviewers were given the opportunity to change their rankings of sites, from the safest to the least safe. In the first iteration, the reviewers identified $40 \%$ of the crash sites as 'least safe', and in the second iteration, the mean accuracy rating increased to $44 \%$. It means that pedestrian safety experts performed only slightly better than chance in correctly identifying the sites of walkalong-roadway crashes based upon visual inspections of their design and information on their operational characteristics. Schneider et al. (2004) used the same data set as for the previous study (Schneider et al. 2001), but used two quantitative techniques (chi-squared and nearest neighbour cluster analyses) to test the null hypothesis that the spatial distribution of risk perceptions is not significantly different from the spatial distribution of police-reported pedestrian crash locations. They finally concluded that the distribution of crash-risk perception is different than reported crash-risk.

Kowtanapanich et al. (2006) organized a seminar entitled 'Public Participation in Black Spot Identification Process' in a local community in Thailand, where they presented the accident situation in the city, engineering means to alleviate road safety problems, viewpoints of a medical expert, and a panel discussion. During the seminar, a questionnaire survey was distributed and participants were asked to identify sites with road safety problems in the municipal area, based on their own perceptions, and to fill in the open-ended questionnaire. 
Reported unsafe locations were validated against those identified via a conventional method based on objective accident data. They concluded that the findings reveal that most locations identified by two or more participants, are indeed Black Spot locations.

Pešić et al. (2012) used the Black Spot identification method in three steps. First step includes identification on the basis of road accident data; the second step includes the identification using conflict technique; the third step includes the identification of sites where road users feel especially unsafe, for which a questionnaire or interview is used. After determining dangerous sites in all the three ways, the 'overlapping' of such determined sites is carried out as a union of all three sets, after which a composite method is applied (sum-of-the-ranks) in order to obtain final ranks of dangerous spots. Survey respondents recognized 7 potentially dangerous locations in total, out of which 4 overlapped with some of 6 locations identified on the basis of road accident data.

Literature review shows that the application of subjective methods for identification of Black Spot is poorly researched. Carried out researches are not methodologically harmonized, while obtained results are different. Karim (1992) concluded that the general public can well rank the actual Black Spot according to the risk level, when a Black Spot is previously known. Austin et al. (1995) found out a very small correlation between the locations identified by the public as dangerous and the sites with many accidents. Duncan et al. (1999) concluded that the experts managed to identify Black Spots using locations pictures only slightly better than the chance alone. Schneider et al. (2001) found out that by applying the subjective method of identification of dangerous locations, the public guessed 2 out of 4 real Black Spots. Schneider et al. (2004) concluded that the perception of risk the public have differs from the real risk obtained on the basis of road accidents. Kowtanapanich et al. (2006) found out a strong correlation between Black Spots identified involving the participation of the public, and objectively identified Black Spots. Pešić et al.
(2012) found out that the general public could detect 4 out of 6 real Black Spots.

A study has been carried out in this paper concerning the possibility of identifying Black Spots on state roads on the basis of drivers' perception of risk and defining a subjective method for the practical application. The results are compared with the results of BSM programme based on objective Black Spot identification method.

\section{Data Collection}

Lipovac et al. (2011) developed and implemented a Black Spot identification model that used data from the written Road Accidents Reports of the Road Traffic Police Stations (RTPS). A total number of 32 Black Spots on category I and II state roads in the Republic of Serbia were obtained. Nine independent road sections containing 12 real Black Spots (out of 32) have been selected for the survey concerning drivers' perception of dangerous locations. This has included road sections that contain 9 locations with the highest road accident risk, according to the criterion based on the Weighted Road Accident Number (WRAN). The risk was calculated as:

$$
W R A N=R A_{S L I}+13 \cdot R A_{S E I}+99 \cdot R A_{F},
$$

where: $R A_{S L I}$ - number of road accidents with slight injuries; $R A_{S E I}$ - number of road accidents with severe injuries; $R A_{F}$ - number of road accidents with fatalities; 13 and 99 - weighting factors based on the social costs of road accidents in Serbia.

Interviews were carried out using randomly selected sample of around 60 drivers per each surveyed road section, where 50 of them included personal vehicle drivers, and 10 were commercial vehicle drivers (heavy goods vehicles and buses). In some cases (if applicable), two surveys were made, the results of which were aggregated. The overview of road sections on which the survey was carried out, with main Black Spots data and conducted surveys, is shown in the Table 1.

Table 1. Data on road sections on which the surveys were carried out, with main data on the sample, Black Spots and Perceived Dangerous Locations (PDLs)

\begin{tabular}{|c|c|c|c|c|c|c|c|c|}
\hline \multirow[b]{2}{*}{$\begin{array}{c}\mathrm{RS}^{*} \\
\text { No }\{j\}\end{array}$} & \multirow[b]{2}{*}{ Road designation and sections } & \multirow{2}{*}{$\begin{array}{c}\text { Perceived } \\
\text { dangerous } \\
\text { locations } \\
\left(P D L_{j}\right)\end{array}$} & \multicolumn{3}{|c|}{ No of respondents } & \multicolumn{3}{|c|}{ No of votes } \\
\hline & & & Total & $\begin{array}{c}\text { Personal } \\
\text { vehicles } \\
\text { drivers }\end{array}$ & $\begin{array}{c}\text { Commercial } \\
\text { vehicles } \\
\text { drivers }\end{array}$ & Total & $\begin{array}{c}\text { Personal } \\
\text { vehicles } \\
\text { drivers }\end{array}$ & $\begin{array}{c}\text { Commercial } \\
\text { vehicles } \\
\text { drivers }\end{array}$ \\
\hline$\{1\}$ & R121, Aleksinac-Zitkovac-Vukanja & 27 & 59 & 52 & 7 & 88 & 78 & 10 \\
\hline$\{2\}$ & M24, Pancevo-Zrenjanin & 23 & 120 & 100 & 20 & 156 & 128 & 28 \\
\hline$\{3\}$ & M21, Sabac-Ruma & 18 & 63 & 52 & 11 & 86 & 73 & 13 \\
\hline$\{4\}$ & M22, Raska-N. Pazar & 11 & 114 & 90 & 24 & 133 & 112 & 21 \\
\hline$\{5\}$ & M1.13-D.II.136, V. Han-Vlasina & 8 & 60 & 46 & 14 & 107 & 91 & 16 \\
\hline$\{6\}$ & R120, Becej-Senta & 11 & 62 & 51 & 11 & 84 & 70 & 14 \\
\hline$\{7\}$ & M19.1, Mali Zvornik-Ljubovija & 16 & 60 & 50 & 10 & 95 & 81 & 14 \\
\hline$\{8\}$ & $\begin{array}{l}\text { R120-R122, Temerin-Backo } \\
\text { Gradiste-Becej }\end{array}$ & 7 & 61 & 53 & 8 & 70 & 58 & 12 \\
\hline$\{9\}$ & R214, Nis-Leskovac & 3 & 60 & 36 & 24 & 71 & 58 & 13 \\
\hline & SUM & 124 & 659 & 530 & 129 & 1197 & 1012 & 185 \\
\hline
\end{tabular}

Note: ${ }^{\star}$ road section. 
Vehicles were stopped by a traffic police officer and, after drivers have given their consent to participating in the survey, the interviewers who were particularly trained to do the interview in an unbiased manner, proceeded with the interview. Only those drivers who knew the surveyed road section were interviewed. Each interviewed driver was asked about the locations on the surveyed section which he/she considered particularly dangerous - PDLs. They were able to report up to three (3) such different sites. No suggestions or explanation about the criteria were given to respondents in order to obtain responds that correspond to real perception while driving.

\section{Method of Analysis}

A discrete random variable $x_{j i}$ was defined for the purpose of this survey. It represents the percentage of respondents who recognized site $P D L_{j i}$ as dangerous on that road section:

$$
x_{j i}=\left(\frac{D_{j i}}{N_{j}}\right) \cdot 100[\%], j=1 \div 9 ; i=1 \div m_{j},
$$

where: $x_{j i}$ - percentage of respondents who stated that the $P D L_{j i}$ is a dangerous location $\left(j=1 \div 9 ; i=1 \div m_{j}\right)$ local frequencies of votes for $P D L_{j i} ; D_{j i}$ - number of respondents who recognized the $P D L_{j i}$ as a dangerous location; $\mathrm{Nj}$ - total number of respondents who were interviewed about dangerous locations on the road section $j ; m_{j}$ - number of PDLs on the road section $j$.

This work gives the analysis of $n=124$ random variables $x_{j i}(j=1 \div 9 ; i=1 \div m)$ :

$$
n=\sum_{j=1}^{9} \sum_{i=1}^{m_{j}} P D L_{j i}=124 .
$$

Values of $x_{j i}$ calculated in this way are adjusted to the local application in real conditions, and to the application of the final model on each particular section.

A set of hypotheses was defined for each examined $P D L_{j i}$. A test was carried out in order to decide whether the null hypothesis stating that a certain $P D L_{j i}$ is not a Black Spot will be rejected. The hypotheses are defined as:

$$
H_{0 j i}: x_{j i}<t\left(P D L_{j i} \text { is a Black Spot }\right) \text { - hypothesis is }
$$
accepted;

$H_{1 j i}: x_{j i} \geq t\left(P D L_{j i}\right.$ is not a Black Spot $)$ - hypothesis is rejected;

where: $t$ is the value of the upper threshold limit of the 'acceptable' frequency of the vote criterion $(0<t \leq 100 \%)$ on $P D L_{j i}$.

For each $x_{j i}$ whose value is lower than the threshold limit value of $t$, the hypothesis saying that the analysed $P D L_{j i}$ is not a Black Spot is acceptable. Contrary to this, the hypothesis will be rejected. For example, on a section $j=5$ (M1.13-D.II.136, V. Han-Vlasina), a $P D L_{51}$ 'Samukovo' has $60 \%$ of all votes obtained on this road section.
If the value of the upper threshold limit of the criterion $t$ was smaller than or equal to $60 \%$, the hypothesis saying that the analysed $P D L_{51}$ is not a Black Spot will be rejected, while for values of $t$ that are higher than $60 \%$, the hypothesis will be accepted (since this location is a Black Spot for all the values of $t$, inclusive of $60 \%$ ).

\subsection{Multiple Hypothesis Testing}

Generally speaking, it is possible to make two types of errors in multiple hypothesis testing: (1) Type I error, when a PDL which is not a Black Spot is identified as Black Spot (false positive) and (2) Type II error, when a PDL which is a Black Spot indeed is identified as a 'non Black Spot' (false negative). Apart from these two outcomes, characterized as errors, it is possible to get two more outcomes that represent a desired testing outcome: when a PDL which is not a Black Spot is identified as a 'non Black Spot' (true negative), and when a PDL which is a Black Spot is identified as it is (true positive). Theoretical bases of the multiple hypothesis testing were offered by many authors (for example, Miranda-Moreno et al. 2007, 2013). Possible outcomes of the research using the multiple hypothesis testing, with the common threshold $t$, for all PDLs ( $n$ tests in total), are given in Table 2 (Miranda-Moreno et al. 2007).

When searching for the optimal common threshold $t$, using the multiple hypothesis testing, the intention is to achieve the optimal relationship between desired (true positive or true negative) and undesired outcomes (false positive or false negative, respectively). A bad choice of the common threshold $t$ can lead to the adverse relationship between the desired and undesired outcomes, i.e. to (1) significant number of PDLs misidentified as Black Spots and (2) significant number of non-identified real Black Spots. The consequence of the first case is a significant and excessive engagement of resources for further analyses of the risk factors on PDLs, while the consequence in the second case is characterized by a definitive 'letting out' of real Black Spots from further examinations of risk sources. While the first case has the ineffective spending of resources as a consequence due to an error, the consequences from the second case are the result of missed opportunities to remove the sources of risks, and to effectively spend the resources and improve road safety.

Following the rules of the multiple hypothesis testing (Table 2), a testing has been done of all $n P D L_{j i}$ $(j=1 \div 9 ; i=1 \div m)$ and values of $t$, in steps of $1 \%(0<t \leq$ $100 \%$ ), in order to make the analysis of the outcome sensitivity (both desired and undesired), depending on the change in the value of $t$.

For each value of $t$, a sum was made for correctly identified PDLs as 'Black Spot' - true positive $S(t)$ and misidentified PDLs as 'Black Spot' - false positive $V(t)$, as well as for misidentified PDLs as 'non Black Spot' false negative $T(t)$ and correctly identified PDLs as 'non Black Spot' - true negative $U(t)$, for all the values of $x_{j i}$ $(j=1 \div 9 ; i=1 \div m)$. Corresponding frequencies of the multiple hypothesis testing outcomes are shown in: 
Table 2. The outcomes of the multiple hypothesis testing with the common threshold $t$ (based on Miranda-Moreno et al. 2007) for $n$ tests

\begin{tabular}{|c|c|c|c|c|}
\hline & \multicolumn{2}{|c|}{ Test results } & \\
\hline & & \# accepted $H_{0}$ (non Black Spot) & $\#$ rejected $H_{0}$ (Black Spot) & \\
\hline \multirow{2}{*}{ 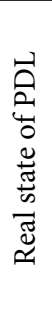 } & $\begin{array}{l}H_{0}: P D L \text { is not } \\
\text { Black Spot }\end{array}$ & $\begin{array}{c}U(t) \\
\text { \# PDLs correctly identified } \\
\text { as 'non Black Spot' } \\
\text { true negative }\end{array}$ & $\begin{array}{c}\qquad(t) \\
\text { \# PDLs misidentified as 'Black Spot' } \\
\text { false positive } \\
\text { type I error }\end{array}$ & $\begin{array}{c}n_{0} \\
\text { \# PDLs that are not } \\
\text { Black Spot } \\
(113)\end{array}$ \\
\hline & \multirow[t]{2}{*}{$\begin{array}{l}H_{1}: P D L \text { is } \\
\text { Black Spot }\end{array}$} & $\begin{array}{c}T(t) \\
\text { \# PDLs misidentified as 'non Black Spot' } \\
\text { false negative } \\
\text { type II error }\end{array}$ & $\begin{array}{c}S(t) \\
\text { \# PDLs correctly identified } \\
\text { as 'Black Spot' } \\
\text { true positive }\end{array}$ & $\begin{array}{c}n_{1} \\
\text { \# PDLs that are Black } \\
\text { Spot } \\
(11)\end{array}$ \\
\hline & & $N-D(t)$ & $\begin{array}{c}D(t) \\
\text { Number of detected Black Spots }\end{array}$ & $\begin{array}{c}n \\
\text { Total \# PDLs } \\
(124)\end{array}$ \\
\hline
\end{tabular}

freq. $V(t)=\frac{V(t) \cdot 100}{n_{0}}[\%]$ - rate of 'false positives': frequency of PDLs misidentified as Black Spot;

freq. $S(t)=\frac{S(t) \cdot 100}{n_{1}}[\%]$ - rate of 'true positives': frequency of PDLs correctly identified as Black Spot;

freq. $U(t)=\frac{U(t) \cdot 100}{n_{0}}[\%]$ - rate of 'true negatives': frequency of PDLs correctly identified as 'non Black Spot';

freq. $T(t)=\frac{T(t) \cdot 100}{n_{1}}[\%]$ - rate of 'false negatives': frequency of PDLs misidentified as 'non Black Spot'.

However, when it comes to such studies, there may be one more, specific outcome, which is not subject to the hypothesis testing, and is not present as such in Ta- ble 2. This is the situation in which a real Black Spot has not been recognized as a PDL during the interview (there were no votes for it - Table 3), and which cannot be subject to hypothesis testing as such, but is in any case necessary to be taken into account when examining desired and undesired outcomes, and when an optimal value of the common threshold $t$ is being required. This outcome is marked as $R(t)$ (number of unidentified Black Spots). Since there is only one Black Spot in this research that is not recognized as PDL, the $R(t)$ will therefore have the value of 1 , i.e. $R(t)=n_{2}=1$ $(0<t \leq 100 \%)$. The total number of sites that will be the subject of analysis, when taking into account unidentified Black Spots, too, will be $D(t)+R(t)$.

In order to include the specific outcome into the optimisation process, new concepts have been introduced representing corresponding frequencies (likelihoods) of the multiple hypothesis testing outcomes, taking into account the specific outcome, too.

Table 3. The overview of main data on Black Spots and PDL

\begin{tabular}{|c|c|c|c|c|c|c|c|}
\hline \multirow{2}{*}{$\begin{array}{l}\mathrm{RS}^{*} \\
\text { No } \\
\{j\}\end{array}$} & \multirow{2}{*}{ Road designation and sections } & \multirow{2}{*}{$\begin{array}{l}\text { Black } \\
\text { Spot No }\end{array}$} & \multirow{2}{*}{ Black spot } & \multirow{2}{*}{ PDL No } & \multirow{2}{*}{ WRAN $^{* *}$} & \multicolumn{2}{|c|}{ Votes as PDL } \\
\hline & & & & & & No & {$[\%]$} \\
\hline \multirow{2}{*}{1} & \multirow{2}{*}{ R121, Aleksinac-Zitkovac-Vukanja } & 1 & Aleksinac-Žitkovac & {$[1]$} & 311 & 2 & 3.4 \\
\hline & & 2 & Curve after the Morava bridge & - & 310 & 0 & 0.0 \\
\hline$\{2\}$ & M24, Pancevo-Zrenjanin & 3 & Crepaja & {$[2]$} & 297 & 32 & 26.7 \\
\hline \multirow{2}{*}{3} & \multirow{2}{*}{ M21, Sabac-Ruma } & 4 & Platičevo-Klenak & [3] & 225 & 3 & 4.8 \\
\hline & & 5 & Curve before highway & {$[4]$} & 212 & 2 & 3.2 \\
\hline \multirow{2}{*}{4} & \multirow{2}{*}{ M22, Raska-N. Pazar } & 6 & Kućani & [5] & 212 & 15 & 13.2 \\
\hline & & 7 & Panojevići & {$[6]$} & 211 & 9 & 7.9 \\
\hline$\{5\}$ & M1.13-D.II.136, V. Han-Vlasina & 8 & Samukovo (Zagužanje) & {$[7]$} & 211 & 36 & 60.0 \\
\hline$\{6\}$ & R120, Becej-Senta & 9 & Bečej (2.5 km section) & [8] & 198 & 57 & 91.9 \\
\hline$\{7\}$ & M19.1, Mali Zvornik-Ljubovija & 10 & Lonjin (Prevoj) & {$[9]$} & 140 & 2 & 3.3 \\
\hline$\{8\}$ & $\begin{array}{l}\text { R120-R122, Temerin-Backo } \\
\text { Gradiste-Becej }\end{array}$ & 11 & $\begin{array}{l}\text { Dangerous curve on } 5 \text { th } \mathrm{km} \\
\text { of R120 road }\end{array}$ & {$[10]$} & 115 & 14 & 23.0 \\
\hline$\{9\}$ & R214, Nis-Leskovac & 12 & Malošište-Novo Groblje & {$[11]$} & 104 & 18 & 30.0 \\
\hline
\end{tabular}

Notes: ${ }^{\star}$ road section; ${ }^{\star *}$ weighted road accident number. 
They are:

- rate of 'positive mishits' (RPM): frequency of mishits when identifying real Black Spot:

freq. $V^{*}(t)=\frac{V(t) \cdot 100}{n_{0}}[\%]$;

- rate of 'positive hits' (RPH): frequency of hits when identifying real Black Spot:

$$
\text { freq. } S^{*}(t)=\frac{S(t) \cdot 100}{n_{1}+n_{2}}[\%] ;
$$

- rate of 'negative hits' (RNH): frequency of hits when identifying real 'non Black Spot':

$$
\text { freq. } U^{*}(t)=\frac{U(t) \cdot 100}{n_{0}}[\%]
$$

- rate of 'negative mishits' (RNM): frequency of mishits when identifying real 'non Black Spot':

$$
\text { freq. } T^{*}(t)=\frac{T(t) \cdot 100}{n_{1}+n_{2}}[\%] \text {. }
$$

Functions of freq. $V(t)$ and freq. $U(t)$ are identical to the corresponding functions of freq. $V^{*}(t)$, freq. $U^{*}(t)$ (respectively), while the functions of freq. $S(t)$ and freq. $T(t)$ differ from the freq. $S^{*}(t)$ and freq. $T^{*}(t)$ (respectively).

\subsection{Optimisation of the Common Threshold}

There are several approaches generally applicable for the optimisation of the common threshold $t$. MirandaMoreno et al. (2007) showed several of them. For instance, Bayesian Test with Weights (BTW), which gives the definition of the function of economic costs of making an error due to a wrong decision on the basis of which a decision is being made whether to accept or reject the hypothesis. Benjamini and Hochberg (1995) proposed the concept based on the error rates that includes procedure of Bayesian hypothesis test with the control of the error rate.

Though the aforementioned optimisation methods take into account correctly the price of type I and II errors, when applied in practice, these data are not available in most cases. Therefore, the authors offer the proposal for simplified optimisation methods surpassing this shortcoming and allowing for an acceptable optimisation in conditions when the mentioned data are missing. Proposed optimisation criteria rely on the minimization of the frequency of mishits (RPM and RNM) and maximization of the frequency of hits ( $\mathrm{RPH}$ and $\mathrm{RNH})$.

With the fresquency of mishits, the optimisation criteria include: equalizing of the frequencies of mishits and minimization of the sum of mishits frequency. First criterion will give $t$ value with balanced error rates while the second will minimize sum of error rates. These optimisation criteria are defined in the following way:

Equalizing of the frequencies of mishits criterion:

$$
\begin{aligned}
& \text { freq. } V^{*}(t)=\text { freq. } T^{*}(t), \\
& 0<t \leq 100 \% .
\end{aligned}
$$

According to this criterion, the optimum threshold is the $t$ for which the RPM is equal to the RNM frequency. The resultant function (LEE) can be defined as:

$$
\begin{aligned}
& L_{E E}=\text { freq. } V^{*}(t) \text { - freq. } T^{*}(t)=0, \\
& 0<t \leq 100 \% .
\end{aligned}
$$

This criterion could be useful in a situations when decision makers need a solution with balanced error rates.

\section{Minimization of the sum of mishits frequency criterion:}

With this criterion, the optimal threshold is defined as the $t$ for which there is a rule that the sum of RPM and RNM is the least for the whole range of $t$. The function of mishits - losses $\left(L_{S m}\right)$ can be defined as:

$$
\begin{aligned}
& L_{S m}=\min \left\{\text { freq. } V^{*}(t)+\text { freq. } T^{*}(t)\right\}, \\
& 0<t \leq 100 \% .
\end{aligned}
$$

Optimisation criteria for the frequency of hits are: equalizing of the frequencies of hits and maximization of the sum of hits frequency. First criterion will give $t$ value with balanced hits rates while the second will maximize sum of hits. These optimisation criteria are defined in the following way:

Equalizing of the frequencies of hits criterion:

$$
\begin{aligned}
& \text { freq. } S^{*}(t)=\text { freq. } U^{*}(t), \\
& 0<t \leq 100 \% .
\end{aligned}
$$

According to this criterion, the optimum threshold is the $t$ for which the RPH is equal to RNH. The resultant function (LHE) can be defined as:

$$
\begin{aligned}
& L_{H E}=\text { freq. } S^{*}(t)-\text { freq. } U^{*}(t)=0, \\
& 0<t \leq 100 \% .
\end{aligned}
$$

This criterion could be useful in a situations when decision makers need a solution with balanced hits rates.

\section{Maximization of the sum of hits frequency criterion}

With this criterion, the optimal threshold is defined as the $t$ for which there is a rule that the sum of RPH and $\mathrm{RNH}$ is the biggest for the whole range of $t$. The function of hits - wins (LSM) can be defined as:

$$
\begin{aligned}
& L_{S M}=\max \left\{\text { freq. } S^{*}+\text { freq. } U^{*}(t)\right\}, \\
& 0<t \leq 100 \% .
\end{aligned}
$$

\section{Results and Discussion}

There are 12 Black Spots on 9 surveyed road sections that have been identified using the objective identification method based on the road accident history (Table 3). Each of the selected road sections has at least one of the most hazardous locations that has been identified according to criterion based on the WRAN (Lipovac et al. 2011). There are two Black Spots on each of the road sections $\{1\},\{3\}$ and $\{4\}$, while there are one Black Spots on each of the remaining road sections (Table 3 ). Black Spots in Table 3 are ranked according to WRAN value. Since each respondent could list up to three PDLs, 
the maximum number of votes for each PDL is equal to the size of the respondent sample per road sections. Out of all 12 Black Spots, respondents detected 11 of them (91.7\%). One Black Spots (the one with a smaller WRAN number on the road section $\{1\}$ ) did not get any vote, i.e. none of the respondents listed that location as a PDL. The overview of Black Spots and the number of votes for certain PDLs is shown in Table 3. Out of the total number of PDLs $(n=124), 11$ are real Black Spots $\left(n_{1}=11\right)$, while $113\left(n_{0}=113\right)$ are not real Black Spots. The total number of sites that will be the subject to optimisation, when taking into account unidentified Black Spots $(D(t)+R(t))$, in the case of the threshold limit of $t=100 \%$, will be equal to $n+n_{2}=n_{0}+n_{1}+n_{2}=125$.

The outcomes of the multiple hypothesis testing are the following: the number of PDLs misidentified as Black Spots $-V(t)$ is the decreasing function with the values from 113 to 0 ; the number of PDLs correctly identified as non Black Spots $-U(t)$ is the increasing function with values from 0 to 113; the number of PDLs correctly identified as Black Spots $-S(t)$ is the decreasing function with the values from 11 to 0 ; and the number of PDLs misidentified as non Black Spots - $T(t)$ is the increasing function with the values from 0 to 11 (Fig. 1).

The frequencies of the multiple hypothesis testing outcomes that take into account the specific outcome (unidentified Black Spot) are shown in the Fig. 2. The function of freq. $V^{*}(t)$ is decreasing with the values from $100 \%$ to 0 , the freq. $U^{*}(t)$ is increasing with the values from 0 to $100 \%$, the freq. $S^{*}(t)$ is decreasing with the values from $92 \%$ to 0 , and the freq. $T^{*}(t)$ is increasing with the values from 0 to $100 \%$.

The following results have been obtained applying the proposed optimisations together with the frequencies of mishits ('positive mishits' and 'negative mishits') and the frequencies of hits ('positive hits' and 'negative hits').

Data fitting for freq. $T^{*}(t)$ and freq. $V^{*}(t)$ with the 3 rd order polynomial regression lines was made for the criterion with the equalizing of frequencies of mishits, and their cross-section found. Since the cross-section is at the beginning of the range $t$, data fitting has been made for the values of $t$ between 0 and 20\%, which enabled the application of the $3 \mathrm{rd}$ order polynomial regression lines with high values of $R^{2}$ (Fig. 3). The functions of the 'rate of negative mishits' and the 'rate of positive mishits' have a common value of $P D L s \approx 35.1 \%$ for the percentage of votes $t=7.7 \%$. For such a calculated optimal $t$, and based on data fit for false positives $(V(t))$ and false negatives $(T(t))$ (Fig. 4), a selection of a total number of 57.9 PDLs was made, which were proclaimed as Black Spots (the number of sites for which the percentage of votes is bigger or equal to 7.7\%). The number of PDLs misidentified as 'Black Spot' (false positives - type I error $-V(t))$ is 50.8, while the number of PDLs misidentified as 'non Black Spot' (false negatives - type II error $-T(t))$ is 3.9. The number of PDLs correctly identified as 'Black Spot' (true positives $-S(t)$ ) is 7.1 while the number of PDLs correctly identified as 'non Black Spot' (true negatives $-U(t)$ ) is 62.2 PDLs.

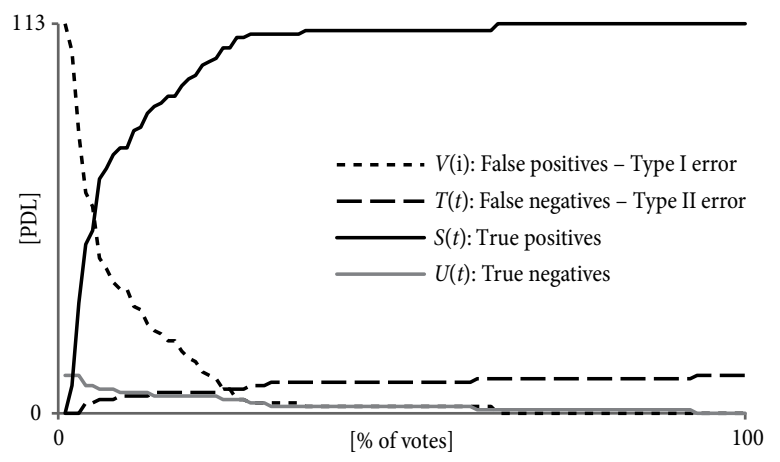

Fig. 1. The outcomes of the multiple hypothesis testing

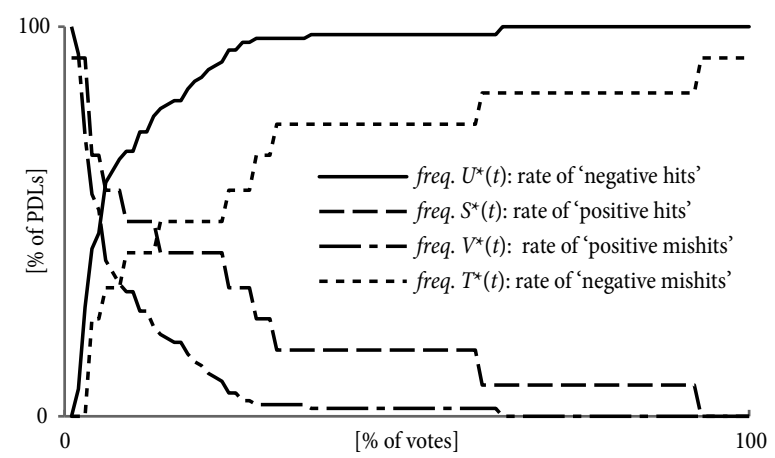

Fig. 2. Frequencies of the multiple hypothesis testing outcomes

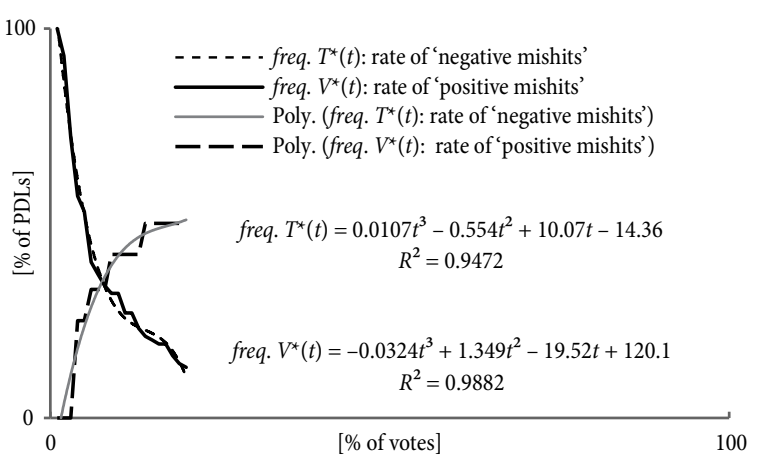

Fig. 3. Optimisation made using equalizing of frequencies of mishits

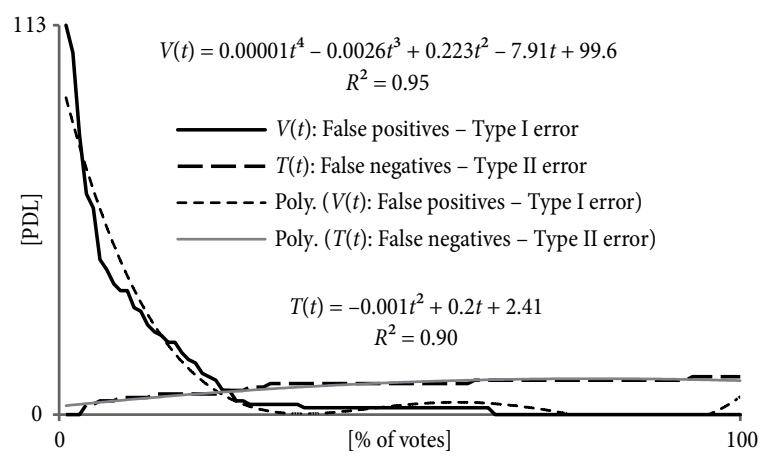

Fig. 4. Data fitting for $T(t)$ and $V(t)$ with the polynomial regression lines 
Data fitting for the freq. $U^{*}(t)$ and freq. $S^{*}(t)$ with the 3 rd order polynomial regression lines was made for the criterion with the equalizing of frequencies of hits, and their cross-section was found. As in previous case, data fitting has been made for the values of $t$ between 0 and $20 \%$ (Fig. 5). The functions of the 'rate of negative hits' and the 'rate of positive hits' have a common value of $P D L s \approx 60 \%$ for the percentage of votes $t=6.7 \%$. On the basis of data fit for true positives $(S(t))$ and true negatives $(U(t))$ (Fig. 6), a selection of a total number of 63.2 PDLs was made. The number of PDLs correctly identified as 'Black Spot' (true positives - $S(t)$ ) is 7.3 while the number of PDLs correctly identified as 'non Black Spot' (true negatives $-U(t)$ ) is 57.1. The number of PDLs misidentified as 'Black Spot' (false positives type I error $-V(t))$ is 55.9 while the number of PDLs misidentified as 'non Black Spot' (false negatives - type II error $-T(t))$ is 3.7 PDLs.

Corresponding functions of the sums have been calculated first (Fig. 7), in accordance with the allocated functions of loss $\left(L_{S m}\right)$ and wins $\left(L_{S M}\right)$, in order to apply the optimisation criterion with the sums of frequencies of mishits and hits.

Data fitting for the resultant function of the sum of freq. $V^{*}(t)$ and freq. $T^{*}(t)$ with the 4 th order polynomial regression lines (Fig. 8) was made for the optimisation criterion with the minimization of the frequency sum of mishits, and its minimum value was found. Data fitting has been done for the values of $t$ between 0 and $31 \%$, as the minimum of the analysed function is within this range. Minimum value of the sum PDLs $=61.3 \%$ is obtained for the percentage of votes of $t=24.7 \%$. On the basis of data fit for the sum of false positives and false negatives $(V(t)+T(t))$ (Fig. 4), a selection of a total number of 9.3 PDLs was made. The number of PDLs misidentified as 'Black Spot' (false positives $-V(t)$ ) is 5.0 while the number of PDLs misidentified as 'non Black Spot' (false negatives - type II error - $T(t)$ ) is 6.7 . The number of PDLs correctly identified as 'Black Spot' (true positives $-S(t)$ ) is 4.3 while the number of PDLs correctly identified as 'non Black Spot' (true negatives $U(t))$ is 108 PDLs.

Data fitting for the resultant function of the sum of freq. $S^{*}(t)$ and freq. $U^{*}(t)$ with the 4 th order polynomial regression line was made for the optimisation criterion with the maximization of the sum of frequencies of hits, and its minimum value was found (Fig. 9). As in the previous case, data fitting has been made for the values of $t$ between 0 and $31 \%$. Maximum value of the percentage sum $P D L s=130.1 \%$ is obtained for the percentage of votes of $t=24.5 \%$. On the basis of data fit for the sum of true positives - $S(t)$ and true negatives - $U(t)$ (Fig. 6), a selection of a total number of 9.6 PDLs was made. The number of PDLs correctly identified as 'Black Spot' (true positives $-S(t)$ ) is 4.4 while the number of PDLs correctly identified as 'non Black Spot' (true negatives $-U(t))$ is 107.8. The number of PDLs misidentified as 'Black Spot' (false positives - $V(t)$ ) is 5.2 while the number of PDLs misidentified as 'non Black Spot' (false negatives - type II error - $T(t))$ is 6.6 PDLs.

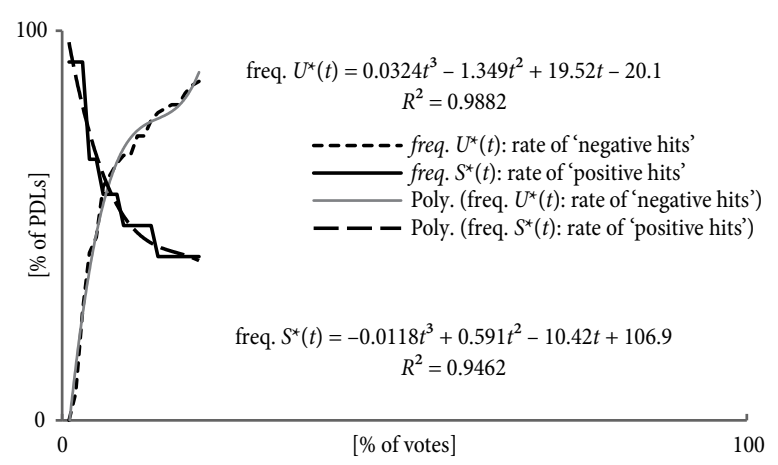

Fig. 5. Optimisation made using equalizing of frequencies of hits

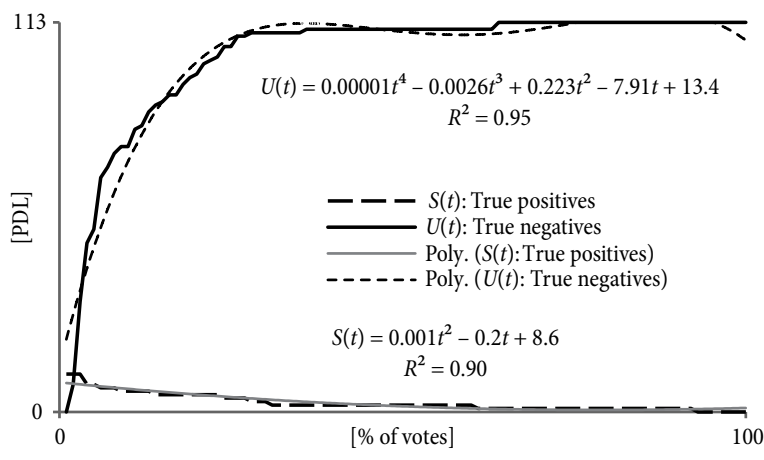

Fig. 6. Data fitting for $U(t)$ and $S(t)$ with the polynomial regression lines

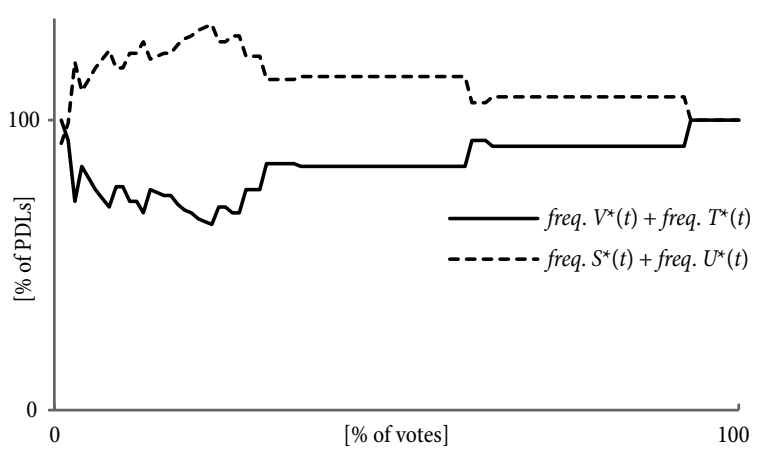

Fig. 7. The sum of frequencies of mishits and the sum of frequencies of hits

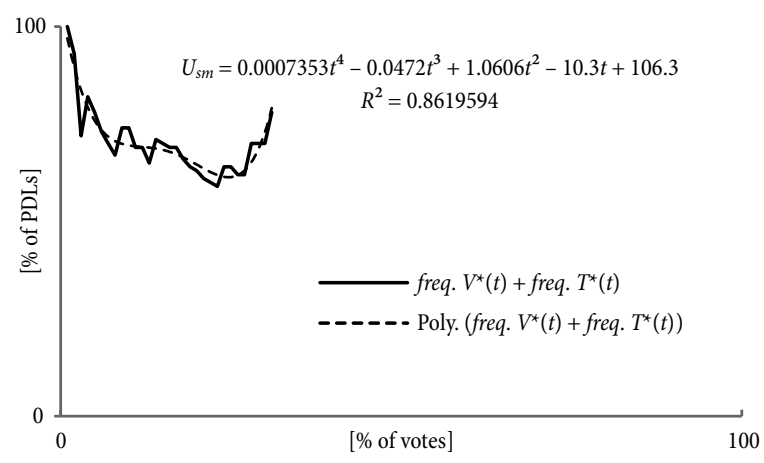

Fig. 8. Optimisation using the minimization of the sum of frequencies of mishits 


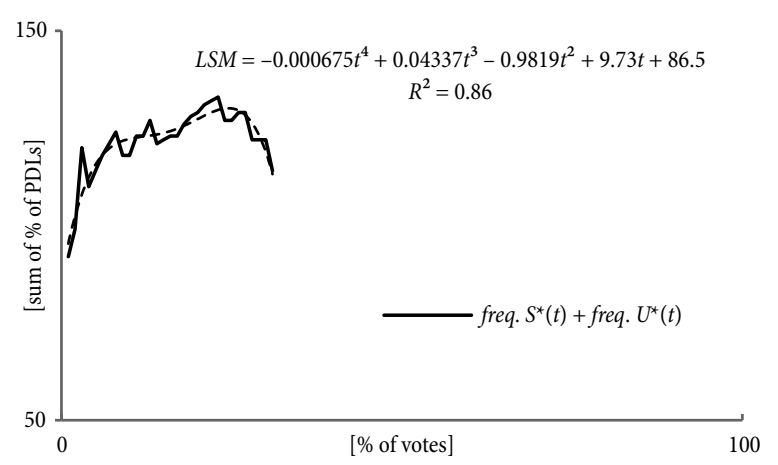

Fig. 9. Optimisation using the maximization of the sum of frequencies of hits

The comparative overview of optimisation results is given in Table 4 .

The results obtained show the similarity of effects in the application of the 'related' optimisation criteria. In the case of applying the optimisation with the equalizing of frequencies (case (1) in ), by setting up the threshold limit of $t=7.7 \%$ for the equalizing of frequencies of mishits, a selection of 57.9 sites was made, while by setting up the threshold limit of $t=6.7 \%$ for the equalizing of frequencies of hits (in case (2)), a selection of 63.2 sites was made. The number of correctly identified sites in the first case is 7.1 (i.e. $12.3 \%$ of selected sites or $59.2 \%$ of all black spots), while in the second case, the number of correctly identified sites is 7.3 (i.e. $11.6 \%$ of selected sites or $60.8 \%$ of all black spots), which represents a small advantage for the optimisation using the equalizing of frequencies of mishits. On the other hand, a wrong selection of $50.8(87.7 \%)$ and 55.9 (88.4\%) sites respectively for these two cases will result in higher analysis costs of identified sites, which would serve for determining the real status of PDLs.

In the case of optimisation with the minimization of the sum of mishits frequency (in case (3)), by setting up the threshold limit of $t=24.7 \%$, a selection of 9.3 sites was made, while by setting up the threshold limit of $t=24.5 \%$ for the optimisation with the maximization of the sum of hits frequency (in case (4)), a selection of 9.6 sites was made. However, 4.3 sites ( $46.2 \%$ of selected and 35.8 of all black spots) out of selected sites in case (3) were correctly identified, while 4.4 black spots ( $43.8 \%$ of selected and $36.7 \%$ of all black spots) out of selected sites in case (4) were correctly identified, which represents a small advantage for the optimisation with maximization of the sum of frequencies of mishits (case 3 ). In these two cases, wrong selection has been made in a significantly smaller number of cases as there are only 5.0 sites (53.8\% of selected sites) in case (3) and 5.2 sites (54.2\%) in case (4).

If the criterion for selection of the best optimisation method was the ratio of correctly identified and misidentified sites (expressed as $1: V(t) / S(t)$ ), then the best method would be the one in case (3) as this case has the most favourable ratio (1:1.16). It means that for each correctly detected Black Spot, only 1.16 of other Black Spots should be unnecessarily analysed. The case (4) follows with a slightly unfavourable ratio of (1:1.24). Methods 1 and 2 are lagging behind significantly, as the ratio in case (1) is 1:7.15, and even 1:7.66 in case (2).

Table 4. The overview of optimisation results

\begin{tabular}{|c|c|c|c|c|c|c|c|c|c|}
\hline & & \multicolumn{8}{|c|}{ Optimisation criteria } \\
\hline & & \multicolumn{2}{|c|}{$\begin{array}{l}\text { (1) } \\
\text { equalizing of } \\
\text { the frequencies } \\
\text { of mishits }\end{array}$} & \multicolumn{2}{|c|}{$\begin{array}{l}\text { (2) } \\
\text { equalizing } \\
\text { of the } \\
\text { frequencies } \\
\text { of hits }\end{array}$} & \multicolumn{2}{|c|}{$\begin{array}{l}\text { (3) } \\
\text { minimization } \\
\text { of the sum } \\
\text { of mishits } \\
\text { frequency }\end{array}$} & \multicolumn{2}{|c|}{$\begin{array}{l}(4) \\
\text { maximization } \\
\text { of the sum of hits } \\
\text { frequency }\end{array}$} \\
\hline & $t[\%]$ & \multicolumn{2}{|c|}{7.7} & \multicolumn{2}{|c|}{6.7} & \multicolumn{2}{|c|}{24.7} & \multicolumn{2}{|c|}{24.5} \\
\hline \multirow{4}{*}{ PDLs [\%] } & freq. $S^{*}(t)$ : rate of 'positive hits' & & & \multicolumn{2}{|c|}{60.1} & & & \multicolumn{2}{|c|}{ * } \\
\hline & freq. $V^{*}(t)$ : rate of 'positive mishits' & \multicolumn{2}{|c|}{35.0} & & & \multirow{2}{*}{\multicolumn{2}{|c|}{\} 61.3}} & & \\
\hline & freq. $T^{*}(t)$ : rate of 'negative mishits' & \multicolumn{2}{|c|}{35.2} & & & & & & \\
\hline & freq. $U^{*}(t)$ : rate of 'negative hits' & & & \multicolumn{2}{|c|}{59.8} & & & \multicolumn{2}{|c|}{ * } \\
\hline \multirow{5}{*}{ PDLs [\#] } & $S(t)$ : true positives & 7.1 & \multirow{2}{*}{\} 57.9} & 7.3 & \multirow{2}{*}{\} 63.2} & 4.3 & & 4.4 & \multirow{2}{*}{\} 9.6} \\
\hline & $V(t)$ : False positives - Type I error & 50.8 & & 55.9 & & 5.0 & \} 9.0 & 5.2 & \\
\hline & $T(t)$ : False negatives - Type II error & 3.9 & \multirow{2}{*}{\} 66.1} & 3.7 & \multirow{2}{*}{\} 60.8} & 6.7 & \multirow{2}{*}{\} 114.7} & 6.7 & \multirow{2}{*}{\} 114.4} \\
\hline & $U(t)$ : True negatives & 62.2 & & 57.1 & & 108 & & 107.8 & \\
\hline & $R(t)$ : Unidentified & \multicolumn{2}{|c|}{1} & \multicolumn{2}{|c|}{1} & \multicolumn{2}{|r|}{1} & \multicolumn{2}{|c|}{1} \\
\hline \multirow{6}{*}{ Effects [\%] } & eff. $S(t)$ : true positives & 12.3 & \multirow{2}{*}{100} & 11.6 & \multirow{2}{*}{100} & 46.2 & 100 & 43.8 & \multirow{2}{*}{100} \\
\hline & eff. $V(t)$ : False positives - Type I error & 87.7 & & 88.4 & & 53.8 & 100 & 54.2 & \\
\hline & eff. $T(t)$ : False negatives - Type II error & 5.9 & \multirow{2}{*}{100} & 6.1 & \multirow{2}{*}{100} & 5.8 & 100 & 5.8 & 100 \\
\hline & eff. $U(t)$ : True negatives & 94.1 & & 93.9 & & 94.2 & 100 & 94.2 & 100 \\
\hline & 1: $V(t) / S(t)$ & & & & 66 & & 1.16 & & 24 \\
\hline & $\begin{array}{r}\% \text { correctly identified black spots of all } \\
\text { black spots }\end{array}$ & & & & .8 & & 35.8 & & .7 \\
\hline
\end{tabular}

Note: ${ }^{*}$ freq. $S^{*}(t=24.5)+$ freq. $U^{*}(t=24.5)=130.1 \%$. 


\section{Conclusions}

This paper investigates the possibility of applying the subjective Black Spot identification method on state roads, based on the research survey of attitudes of drivers concerning PDLs on the road, which is methodologically different from those applied by previous researchers. Based on the results of the research survey, and on data on actual Black Spot taken from the previously conducted research (Lipovac et al. 2011), in which the identification was made using the objective method, several models were introduced for selecting the optimal number (percentage) of votes for detecting Black Spot on the basis of surveyed attitudes of drivers on PDLs on the road.

The Bayesian multiple hypothesis testing has been used for the search of the optimal number (or percentage) of votes and all typical outcomes were analysed (false positive, false positive, true negative and false negatives), including the specific outcome (unidentified Black Spot) which takes into account the possibility that a real Black Spot is not identified as PDL by interviewed drivers. In order to use this outcome in the optimisation of the optimal percentage for detecting Black Spots, new terms have been introduced (rates of: positive mishits, positive hits, negative hits and negative mishits). Optimisation is carried out according to the following criteria: (1) equalizing of the frequencies of mishits; (2) equalizing of the frequencies of hits; (3) minimization of the sum of mishits frequency; (4) maximization of the sum of hits frequency.

The analysis has shown that with the selection of the upper threshold limit of the frequency of votes of $t=24.7 \%$ the identification would be carried out with the least relative mishits (those PDLs that were identified as Black Spots, but they are not, and those identified as non Black Spots, but are real Black Spots). The example of data used in the analysis shows that with the selection of $t=24.7 \%$, a total number of 9.6 PDLs would be selected, for which additional analysis should be made in order to determine whether they are Black Spots or not. 4.4 Black Spots (out of the total number of 12) would be successfully identified, while 5.2 PDLs would be misidentified as Black Spots.

On the other hand, by selecting the upper threshold limit of the frequency of votes of $t=7.7 \%$, the identification would be made with the equalized relative mishits (frequency of mishits of around 35\%), while for selection of $t=6.7 \%$, the identification would be made with the equalized relative hits (frequency of hits of around $60 \%)$. The example of this research shows that with the selection of $t=7.7 \%$ a total number of 57.9 PDLs would be identified, for which additional analysis should be made in order to determine whether they are Black Spots or not. 7.1 Black Spots (out of the total number of 12) would be successfully identified, while 50.8 PDLs would be misidentified as Black Spots.

Two optimal solutions are thus offered, applicable in practice, where their selection will depend on concrete circumstances. If the effectiveness in spending the funds is important in conditions of carrying out a re- search with limited resources, then the advantage would be on the side of selected $t=24.7 \%$. On the other hand, if the goal is to detect the majority of real Black Spots, regardless of the fact that this would increase the costs because of a large number of PDLs analysed, then the selection of $t=7.7 \%$ would be given priority.

In any case, it should be mentioned that the starting point for the making of this analysis was the fact that all outcomes are equally valued. The operational application could face with the request to give higher value to missed Black Spots (false negatives) than to misidentified Black Spots (false positives). In that situation the BTW should be applied.

Since the sample size of analysed Black Spots is not so large ( 9 road sections with 12 black spots), it is advisable, before any practical application, to make validation of presented results in accordance to custom circumstances.

Presented subjective based identification method is not seen as an alternative to an objective identification method, but it is usable as a standalone method in situations where data about the accident history are not available, and objective identification method can't be used.

In a practical application of presented subjective identification method, road section without identified Black Spots would be also used for a survey. In order to further improve obtained results it is necessary to carry out validation work with inclusion of road sections without identified Black Spots.

Further studies will use the same data to test the sensitivity of results with regard to different evaluation of votes (by allocating various weights), by amateur and professional drivers.

\section{Acknowledgements}

This work has been supported by the Ministry of Education, Sciences and Technological Development of Republic of Serbia, grant number TR 36007.

\section{References}

Anderson, T. K. 2009. Kernel density estimation and K-means clustering to profile road accident hotspots, Accident Analysis \& Prevention 41(3): 359-364.

http://doi.org/10.1016/j.aap.2008.12.014

Austin, K.; Tight, M.; Kirby, H. 1995. An advanced system for the study of children's safety on the journeys to and from school, in Road Safety in Europe and Strategic Highway Research Program (SHRP), 26-28 September 1994, Lille, France, 2A(3): 99-116.

PIARC. 2003. Road Safety Manual 2003: Recommendations from the World Road Association (PIARC).

Benjamini, Y.; Hochberg, Y. 1995. Controlling the false discovery rate: a practical and powerful approach to multiple testing, Journal of the Royal Statistical Society: Series B (Methodological) 57(1): 289-300.

CEDR. 2008. Tools for Infrastructure Safety Management: Fact Sheets and Common Conclusions. Conference of European Directors of Roads (CEDR). Brussels, Belgium. 30 p. Available from Internet: http://www.cedr.fr/home/fileadmin/ user_upload/en/Thematic_Domains/Strat_plan_1_20052009/3_TD_Operation/1_TG_Road_Safety/7_Iceland_24_26-09-08/Minutes/11a_Report_Tools.pdf 
De Luca, M.; Mauro, R.; Russo, F.; Dell'Acqua, G. 2011. Beforeafter freeway accident analysis using cluster algorithms, Procedia - Social and Behavioral Sciences 20: 723-731. http://doi.org/10.1016/j.sbspro.2011.08.080

Dell'Acqua, G.; Russo, F. 2010. Speed factors on low-volume roads for horizontal curves and tangents, The Baltic Journal of Road and Bridge Engineering 5(2): 89-97. http://doi.org/10.3846/bjrbe.2010.13

Dell'Acqua, G.; Russo, F. 2011. Safety performance functions for low-volume roads, The Baltic Journal of Road and Bridge Engineering 6(4): 225-234. http://doi.org/10.3846/bjrbe.2011.29

Duncan, C.; Khattak, A.; Hughes, R. 1999. The Perceived Effectiveness of Sidewalks and Other Pedestrian Safety Treatments as Countermeasures for Hit-Along-Roadway Crashes. Highway Safety Research Centre, University of North Carolina, US.

Elvik, R. 1988. The perceived effectiveness of sidewalks and other pedestrian safety treatments, in Proceedings of the International Symposium on Traffic Safety Theory and Research Methods, 26-28 April 1988, Amsterdam, The Netherlands.

Elvik, R. 2003. Traffic safety, in M. Kutz (Ed). Handbook of Transportation Engineering. McGrawHill.

Elvik, R. 2007. State-of-the-Art Approaches to Road Accident Black Spot Management and Safety Analysis of Road Networks. ТØI Report 883/2007, The Institute of Transport Economics (TØI), Oslo, Norway. 126 p.

ERF. 2002a. Good Practice Guidelines to Infrastructural Road Safety. European Union Road Federation (ERF). 62 p.

ERF. 2002b. Guidelines to Black Spot Management: Identification and Handling. European Union Road Federation (ERF). 27 p.

Flahaut, B.; Mouchart, M.; Martin, E. S.; Thomas, I. 2003. The local spatial autocorrelation and the kernel method for identifying black zones: a comparative approach, Accident Analysis \& Prevention 35(6): 991-1004. http://doi.org/10.1016/S0001-4575(02)00107-0

Fukuda, T.; Tangpaisalkit, C.; Ishizaka, T.; Sinlapabutra, T.; Fukuda, A. 2005. Empirical study on identifying potential black spots through public participation approach: a case study of Bangkok, Journal of the Eastern Asia Society for Transportation Studies 6: 3683-3696. http://doi.org/10.11175/easts.6.3683

Geurts, K.; Wets, G. 2003. Black Spot Analysis Methods: Literature Review. Report RA-2003-07. Policy Research Centre for Traffic Safety, Diepenbeek, Belgium. 30 p.

Hauer, E. 1996. Identification of sites with promise, Transportation Research Record: Journal of the Transportation Research Board 1542: 54-60. http://doi.org/10.3141/1542-09

Karim, M. R. 1992. Traffic accidents in a university environment, ITE Journal 62(7): 30-34.

Kowtanapanich, W.; Satiennam, T.; Rattanasuteerakul, K.; Somudom, T. 2011. Public participation approach for the rural community black spot improvement, experiences from Thailand, Proceedings of the Eastern Asia Society for Transportation Studies 8: 1-13. http://doi.org/10.11175/eastpro.2011.0.371.0

Kowtanapanich, W.; Tanaboriboon, Y.; Chadbunchachai, W. 2006. Applying public participation approach to black spot identification process: a case study in Thailand, IATSS Research 30(1): 73-85.

http://doi.org/10.1016/S0386-1112(14)60158-8

Lipovac, K.; Nešić, M.; Vujanić, M.; Pešić, D.; Antić, B. 2011. Prikupljanje podataka o opasnim mestima ${ }^{1}$. Kriminalisticko policijska akademija, Republika Srbija. (in Serbian).

Lipovac, K.; Nešić, M.; Jovanović, D. 2009. Identifikacija "crnih tačaka" na putevima, in 8 . Međunarodna konferencija "Unapređenje policijskih poslova u bezbednosti saobraćaja" 11.-13. novembra 2009, Vrnjačka Banja, Republika Srbija, 161-174. (in Serbian).

Mauro, R.; De Luca, M.; Russo, F.; Dell'Acqua, G. 2013. Using a $\mathrm{k}$-means clustering algorithm to examine patterns of vehicle crashes in before-after analysis, Modern Applied Science 7(10): 11-19. http://doi.org/10.5539/mas.v7n10p11

Miranda-Moreno, L. F.; Labbe, A.; Fu, L. 2007. Bayesian multiple testing procedures for hotspot identification, Accident Analysis \& Prevention 39(6): 1192-1201.

http://doi.org/10.1016/j.aap.2007.03.008

Miranda-Moreno, L. F.; Heydari, S.; Lord, D.; Fu, L. 2013. Bayesian road safety analysis: incorporation of past evidence and effect of hyper-prior choice, Journal of Safety Research 46: 31-40. http://doi.org/10.1016/j.jsr.2013.03.003

Pešić, D.; Vujanić, M.; Lipovac, K.; Antić, B. 2012. An integrated method of identifying and ranking danger spots for pedestrians on microlocation, Transport 27(1): 49-59. http://doi.org/10.3846/16484142.2012.664826

Russo, F.; Biancardo, S. A.; Dell'Acqua, G. 2014. Consistent approach to predictive modeling and countermeasure determination by crash type for low-volume roads, The Baltic Journal of Road and Bridge Engineering 9(2): 77-87. http://doi.org/10.3846/bjrbe.2014.10

Schneider, R.; Khattak, A.; Zegeer, C. 2001. Method of improving pedestrian safety proactively with geographic information systems: example from a college campus, Transportation Research Record: Journal of the Transportation Research Board 1773: 97-107. http://doi.org/10.3141/1773-12

Schneider, R. J.; Ryznar, R. M.; Khattak, A. J. 2004. An accident waiting to happen: a spatial approach to proactive pedestrian planning, Accident Analysis \& Prevention 36(2): 193-211. http://doi.org/10.1016/S0001-4575(02)00149-5

Sørensen, M. 2007. Best Practice Guidelines on Black Spot Management and Safety Analysis of Road Networks. TØI Report 898/2007, The Institute of Transport Economics (TØI), Oslo, Norway. 80 p.

Sørensen, M.; Elvik, R. 2007. Black Spot Management and Safety Analysis of Road Networks - Best Practice Guidelines and Implementation Steps. ТØI Report 919/2007, The Institute of Transport Economics (TØI), Oslo, Norway. 118 p.

Vujanić, M.; Lipovac, K.; Nešić, M.; Jovanović, D.; Antić, B.; Pešić, D. 2008. Metodologija identifikacije i upravljanja opasnim mestima (crnim tačkama) na državnim putevima Republike Srbije. Saobraćajni fakultet, Univerzitet u Beogradu. 265 1. (in Serbian).

Xie, Z.; Yan, J. 2013. Detecting traffic accident clusters with network kernel density estimation and local spatial statistics: an integrated approach, Journal of Transport Geography 31: 64-71. http://doi.org/10.1016/j.jtrangeo.2013.05.009

\footnotetext{
${ }^{1}$ This is a study of black spots identification and data collection on state roads of Serbia. Serbia has a black spot data base and, in this study, black spots were identified, data on them were collected and entered directly into the data base. There is no public written report.
} 